\title{
Risk factors associated with medial tibial stress syndrome in runners: a systematic review and meta-analysis
}

This article was published in the following Dove Press journal:

Open Access Journal of Sports Medicine

12 November 2013

Number of times this article has been viewed

\section{Phil Newman \\ Jeremy Witchalls \\ Gordon Waddington \\ Roger Adams}

Faculty of Health, Physiotherapy, University of Canberra, Bruce, ACT, Australia
Correspondence: Phil Newman Faculty of Health, Physiotherapy, University of Canberra, Bruce,

ACT 260I, Australia

Tel +612 620I 283 I

Fax +6I2620I 5727

Email phillip.newman@canberra.edu.au
Background: Medial tibial stress syndrome (MTSS) affects 5\%-35\% of runners. Research over the last 40 years investigating a range of interventions has not established any clearly effective management for MTSS that is better than prolonged rest. At the present time, understanding of the risk factors and potential causative factors for MTSS is inconclusive. The purpose of this review is to evaluate studies that have investigated various risk factors and their association with the development of MTSS in runners.

Methods: Medical research databases were searched for relevant literature, using the terms "MTSS AND prevention OR risk OR prediction OR incidence".

Results: A systematic review of the literature identified ten papers suitable for inclusion in a meta-analysis. Measures with sufficient data for meta-analysis included dichotomous and continuous variables of body mass index (BMI), ankle dorsiflexion range of motion, navicular drop, orthotic use, foot type, previous history of MTSS, female gender, hip range of motion, and years of running experience. The following factors were found to have a statistically significant association with MTSS: increased hip external rotation in males (standard mean difference [SMD] 0.67, 95\% confidence interval [CI] 0.29-1.04, $P<0.001$ ); prior use of orthotics (risk ratio [RR] 2.31, 95\% CI 1.56-3.43, $P<0.001$ ); fewer years of running experience (SMD $-0.74,95 \%$ $\mathrm{CI}-1.26$ to $-0.23, P=0.005$ ); female gender (RR $1.71,95 \%$ CI $1.15-2.54, P=0.008$ ); previous history of MTSS (RR 3.74, 95\% CI 1.17-11.91, $P=0.03$ ); increased body mass index (SMD $0.24,95 \%$ CI $0.08-0.41, P=0.003$ ); navicular drop (SMD 0.26, 95\% CI 0.02-0.50, $P=0.03$ ); and navicular drop $>10 \mathrm{~mm}$ (RR 1.99, 95\% CI 1.00-3.96, $P=0.05$ ).

Conclusion: Female gender, previous history of MTSS, fewer years of running experience, orthotic use, increased body mass index, increased navicular drop, and increased external rotation hip range of motion in males are all significantly associated with an increased risk of developing MTSS. Future studies should analyze males and females separately because risk factors vary by gender. A continuum model of the development of MTSS that links the identified risk factors and known processes is proposed. These data can inform both screening and countermeasures for the prevention of MTSS in runners.

Keywords: medial tibial stress syndrome, injury prevention, risk factors, running injuries

\section{Background}

Medial tibial stress syndrome (MTSS) is usually brought on by running or impact loading of the lower limb, and the resulting pain will typically limit running activity. MTSS is generally considered to be a discrete clinical entity that is differentiated from chronic exertional compartment syndrome, stress fracture, popliteal artery entrapment syndrome, and the various neuropathies. Coexistence and interrelationships of these entities is acknowledged but not clearly understood. ${ }^{1}$ Inconsistent use of terminology, 
such as "shin splint syndrome" and "soleus enthesopathy", is evident in the historic and current literature, and it is likely that such variation in nomenclature has contributed to the current lack of understanding of the condition., ${ }^{2,3}$

A range of hypotheses has been proposed in regard to the anatomic structures most likely to be the source of pain in MTSS, with myofascial strain, enthesopathy, periosteal inflammation, and bone stress reaction theories most prevalent. Histologic studies have been small, and very few have identified inflammatory markers within the periosteal margins with any consistency to support the periostitis

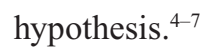

Cadaveric studies of the myofascial anatomy are inconsistent as to which myofascial element is involved. ${ }^{8-11}$ There is large variation in the site of attachment of the deep crural fascia, soleus, flexor digitorum longus, and tibialis posterior, and there is contention about how well these attachments relate to the site of pain in MTSS. One larger study (50 legs) found a predominant absence of myofascial attachment at the medial tibial border where MTSS pain occurs. ${ }^{11}$ However, posteromedial muscular tenderness is a consistent clinical feature of the syndrome. It may be that this tenderness is a consequence of muscular overuse and chronic fatigue. Whether this is a primary cause or an effect of the condition remains unclear. ${ }^{12,13}$

Recent interpretation arising from imaging and related studies suggests bone stress reaction to be the most likely cause of symptoms in MTSS. ${ }^{14-20}$ Advances in computed tomography, dual energy X-ray absorptiometry, and magnetic resonance imaging techniques have enabled researchers to identify marrow edema consistently, periosteal lifting due to underlying bone exudate, and bony resorption of the posteromedial tibial border in MTSS. The accuracy of the different techniques varies greatly and may be dependent on the timing of imaging in relation to injury onset. ${ }^{21,22}$ Only a limited number of histologic studies have included bone biopsy, but these positively confirm bone stress markers. ${ }^{6,7}$ Some imaging studies demonstrate bony lesions associated with a clinical diagnosis of MTSS in sites such as the proximal tibia and the anterolateral tibial cortex, that are inconsistent with clinically significant sites of pain, ${ }^{3,19}$ and this raises questions about the differential diagnosis of MTSS as well as about the nature of the pathology itself.

It is probable that a combination of structures are involved in MTSS, and some authors have suggested grading systems based on this premise (Figure 1). ${ }^{1}$ A clear understanding of the pathology is needed for future studies, and particularly in regard to the development of targeted intervention strategies.

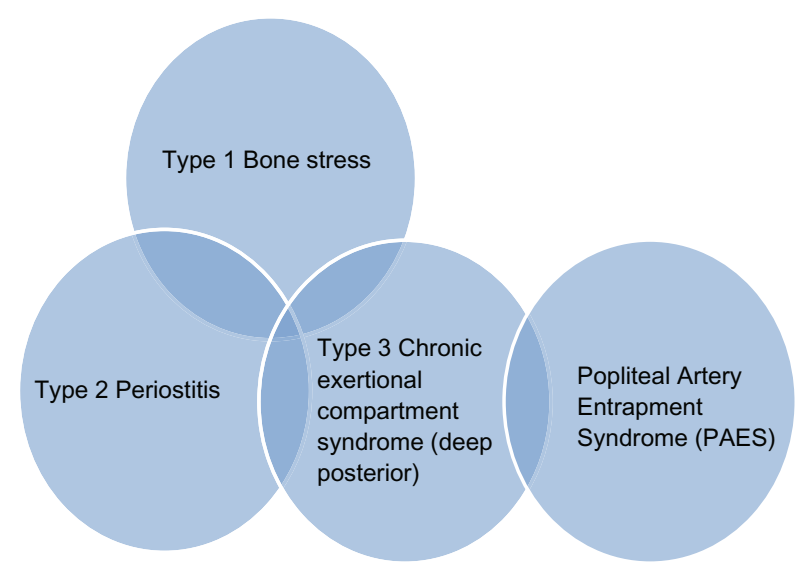

Figure I Traditional differential diagnosis and classification of medial tibial stress syndrome.

Note: Concept from Detmer.'

Recovery times in MTSS tend to be long. A recent randomized controlled trial found that subjects from a nonmilitary sample of runners, in 3 treatment groups, took an average of 102-118 (SD 52-64) days to recover sufficiently to complete an 18-minute run. ${ }^{23}$ Times between 250 and 300 days were taken for $90 \%$ of these participants to recover sufficiently to complete an 18-minute run. This timeframe should influence most clinicians' prognostic planning and education of patients. Trials investigating a range of interventions for MTSS have not as yet established any clearly effective management that is better than prolonged reduction and management of load. ${ }^{2,23-25}$

Several authors have sought to investigate the risk factors associated with the condition with a view to developing screening and preventive countermeasures for MTSS. The variables investigated in these studies fall into categories of range of motion (ROM) and muscle length measures, including joints from hip to hallux, static posture of lower limb segments, kinematic analyses of the lower limb, muscle strength and endurance, running volumes, anthropometric measures, dietary, hormonal, and smoking status, past history of injury, and orthotic and shoe use (Table 1). The majority of the papers that have reported investigations of these associations have been case-control or retrospective in design, thus raising questions about the attribution of cause and effect.

To the present time, no meta-analysis has been performed to investigate the associations of various risk factors and the prospective development of MTSS. Therefore, the aim of this review was to identify quality prospective studies that have investigated risk factors for MTSS in runners and to combine their results through meta-analysis. 
Table I Risk factors investigated for association with MTSS in runners in the literature

\begin{tabular}{|c|c|}
\hline Risk factor & References \\
\hline Hip ROM & $31,38,70-73$ \\
\hline Ankle ROM & $|2,3|, 34,38,70-74$ \\
\hline Knee ROM & $38,7 \mid-73$ \\
\hline Rear/forefoot ROM & $34,38,70-73$ \\
\hline Hallux ROM & $72-74$ \\
\hline $\begin{array}{l}\text { Hamstring length, gastrocnemius length, } \\
\text { soleus length }\end{array}$ & $38,73-75$ \\
\hline Leg length & $70,74,76$ \\
\hline $\mathrm{Q}$ angle & 31 \\
\hline Tibial varus/valgus & $34,38,75$ \\
\hline Static genu varus/valgus & $31,38,71,76$ \\
\hline $\begin{array}{l}\text { Static calcaneal varus/valgus, standing foot angle } \\
\text { qualitative and instrumented }\end{array}$ & $38,71,73,75,76$ \\
\hline Static arch height/Foot Posture Index ${ }^{32} /$ foot typing & $12,70,7 \mid, 76,77$ \\
\hline $\begin{array}{l}\text { Navicular drop test/navicular drop test } \\
\text { difference/navicular drop test }>\mathrm{x}\end{array}$ & $31,34,37,38,73,75,78$ \\
\hline Dynamic genu varus/valgus & $37,38,72$ \\
\hline Dynamic calcaneal varus/valgus & $33,35,37,38,72$ \\
\hline $\begin{array}{l}\text { Dynamic plantar pressure plate data: pronated } \\
\text { versus supinated at various phases of gait, } \\
\text { time to peak heel rotation }\end{array}$ & $33,35,37,38,72,74$ \\
\hline Plantar flexor endurance & 78,79 \\
\hline Strength PF/DF/inversion/eversion & 34,38 \\
\hline Strength hip abduction & $31,38,73$ \\
\hline Lean calf girth & 70,73 \\
\hline Mileage per unit time (weeks, months) & 34,77 \\
\hline Running experience years & $34,75,77,80$ \\
\hline Run times per unit distance/fitness & 33,70 \\
\hline Time per week running & 12 \\
\hline Previous history of MTSS & $12,34,78,80$ \\
\hline Previous history of stress fracture & 34,78 \\
\hline Previous history of lower leg injury & $34,77,78$ \\
\hline Orthotic use & $34,70,78,80$ \\
\hline Menstrual regularity & 34 \\
\hline BMI & $31,33,70,77,78,80$ \\
\hline Gender & $|3,3|, 75,78,80$ \\
\hline Height & $31,33,70,80$ \\
\hline Shin pain on palpation in asymptomatic MTSS & 13 \\
\hline Shin edema on palpation in asymptomatic MTSS & 13 \\
\hline Claw toe & 53 \\
\hline $\begin{array}{l}\text { Neuromuscular control deficit of intrinsic } \\
\text { foot muscles }\end{array}$ & $46,47,53$ \\
\hline Straight leg raise & 31 \\
\hline Smoking & 33 \\
\hline
\end{tabular}

Abbreviations: BMI, body mass index; PF, plantar flexion; DF, dorsiflexion; MTSS, medial tibial stress syndrome; ROM, range of motion.

\section{Methods}

\section{Criteria for considering studies for this review \\ Types of studies}

We selected papers that were of prospective design and investigated a range of biometric variables and their associations with MTSS. Explicit criteria for diagnosis of MTSS had to be described in each paper with sufficient detail to exclude stress fracture and ischemic causes. All participants in all papers were runners or played sports that were runningbased. All participants had to be asymptomatic at the time of baseline testing.

To enable calculation of combined results, the papers included had to report MTSS group and non-MTSS group scores, standard deviations, and sample sizes, or sufficient alternative data for these to be calculated. Categorical data had to include the sample sizes in each matrix cell.

Quality of the papers was assessed using a combination of the Quality Index ${ }^{26}$ and Revman5 (Cochrane) criteria (see Figure 2). Each criterion was applied to each paper, and a classification of "low-risk" was assigned where the paper had clearly met the criterion. "Unclear risk" was assigned where there was insufficient detail to determine if the criterion was met or not, and "high-risk" where the criterion was unlikely to be met or bias was highly likely.

\section{Types of participants}

The 1,924 participants in the final selection of studies included runners from military and recreational groups, and tennis, volleyball, track and field, and soccer players.

\section{Electronic searches}

The CINAHL, SPORTDiscus, Pedro, PubMed Central, and Cochrane databases were searched using keyword search terms (keyword contains "medial tibial stress syndrome"

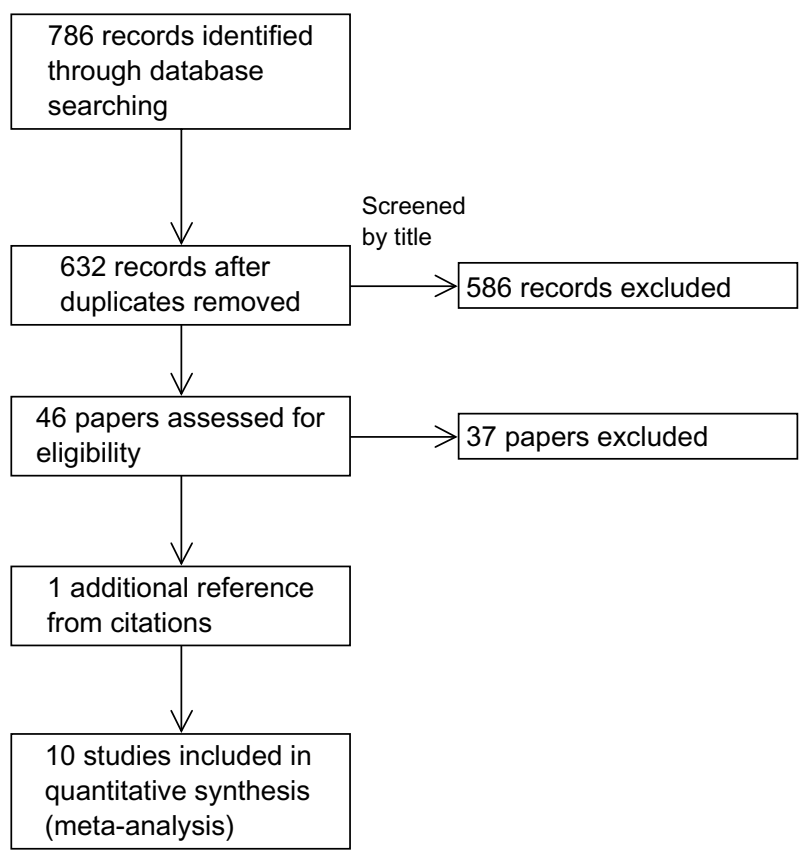

Figure 2 Papers selected from initial search to final inclusion. 
AND keyword contains "prevention" OR "risk" OR "prediction" OR “incidence"). No date limits were applied and the search was completed in March 2013. The resulting references from each database search were combined.

Papers were filtered in accordance with the sequence in Figure 2.

\section{Data extraction and management}

Each included paper was searched for raw scores and group numbers for a range of measured risk factors. Where two or more papers reported the same type of risk factor or measure, the results were combined and analyzed using Review Manager (RevMan version 5.2; Copenhagen, Denmark: The Nordic Cochrane Centre, The Cochrane Collaboration, 2012). Standard mean differences (SMDs) or pooled risk ratios (RRs) were generated to determine the pooled effect size of each risk factor. The random effects model was applied when $I^{2}$ tests for heterogeneity were moderate to high $(>25 \%) .{ }^{27}$ When heterogeneity was low $(\leq 25 \%)$, fixed effects modeling was applied. Effect sizes for each continuous variable were defined as trivial $(0-0.2)$, small $(0.2-0.6)$, moderate $(0.6-1.2)$, large (1.2-2.0), or very large $(>2.0) .{ }^{28}$ Effect sizes for each RR were likewise defined as trivial (1-1.2), small (1.2-1.9), moderate (1.9-3.0), large (3.0-5.7), or very large $(>5.7) .^{28}$

The $P$-value for significance of the pooled effects analyses was set at $\leq 0.05$. Funnel plots were constructed where four or more studies were included in the meta-analysis to assess the influence of publication bias when the $P$-value was $\geq 0.05$. The study authors were emailed to request original data when raw scores or group data were not recorded in the paper; however, no additional data were made available to be included in meta-analyses.

\section{Results \\ Description of studies}

The initial database search found 768 articles that matched the search terms. After predefined exclusion criteria were applied, ten papers were identified for meta-analysis (Figure 2). Studies excluded at the abstract review or full text review stage were either retrospective or case-control designs that would be unable to differentiate cause or effect relationships. The risk of bias in these papers was high due to failure to blind assessors. Some papers were excluded due to nonspecific differentiation of lower leg pain and MTSS. Some variables within the final ten papers were collected only at diagnosis, so these variables were not analyzed. The quality of the final ten papers was high against the criteria applied (Figure 3). A total of 13 variables were able to be pooled for analysis (Table 2).

\section{Risk factors and associations with MTSS Navicular drop}

Four papers reported results of the navicular drop test measured in millimeters. This is a test that measures the difference in height of the navicular tuberosity in the subtalar neutral stance position and the height of the navicular tuberosity in relaxed stance. ${ }^{29,30}$ Three of the four papers measured navicular drop with feet shoulder width apart, and one paper performed the measurement in tandem stance position. ${ }^{31}$ This test was found to be significantly associated with MTSS injury (SMD 0.26, 95\% confidence interval [CI] 0.02-0.50, $P=0.03$, Figure 4). The meta-analysis indicates that a larger navicular drop is associated with increased risk of MTSS.

\section{Navicular drop $>10 \mathrm{~mm}$}

Two papers evaluated a dichotomous variable of navicular drop greater than $10 \mathrm{~mm}$. This test was found to be significantly associated with MTSS injury (Figure 5). Those with a navicular drop $>10 \mathrm{~mm}$ are 1.99 times more likely to develop MTSS than not (RR 1.99, 95\% CI 1.00-3.96, $P=0.05$ ). The meta-analysis also indicates that a larger navicular drop is associated with increased risk of MTSS.

\section{Pronated foot type}

Three studies reported classification by foot type in their papers. In two studies, this was done using either all or part of the Foot Posture Index..$^{32}$ The Foot Posture Index aggregates categorical scores from six domains of foot classification, ie, talar head palpation, malleolar curve, calcaneal position, prominence of talonavicular joint, congruence of medial longitudinal arch, and abduction/adduction of the forefoot on rearfoot. Aggregated scores are then used to classify the foot into pronated, normal, or supinated categories. In a study reported by Sharma et al, ${ }^{33}$ foot type was classified according to pressure plate data that determined proportion of medial to lateral foot pressure during a barefoot walking task. For the purposes of this analysis, the results were pooled and compared on a derived dichotomous variable of "pronated" or "not pronated". This measure was not found to be a significant predictor of MTSS (RR 1.61, 95\% CI $0.37-6.98, P=0.52$ )

\section{Orthotic use}

Three of the papers included in this review surveyed participants on their prior orthotic insole use. A total of 403 participants were surveyed. Those who had used 


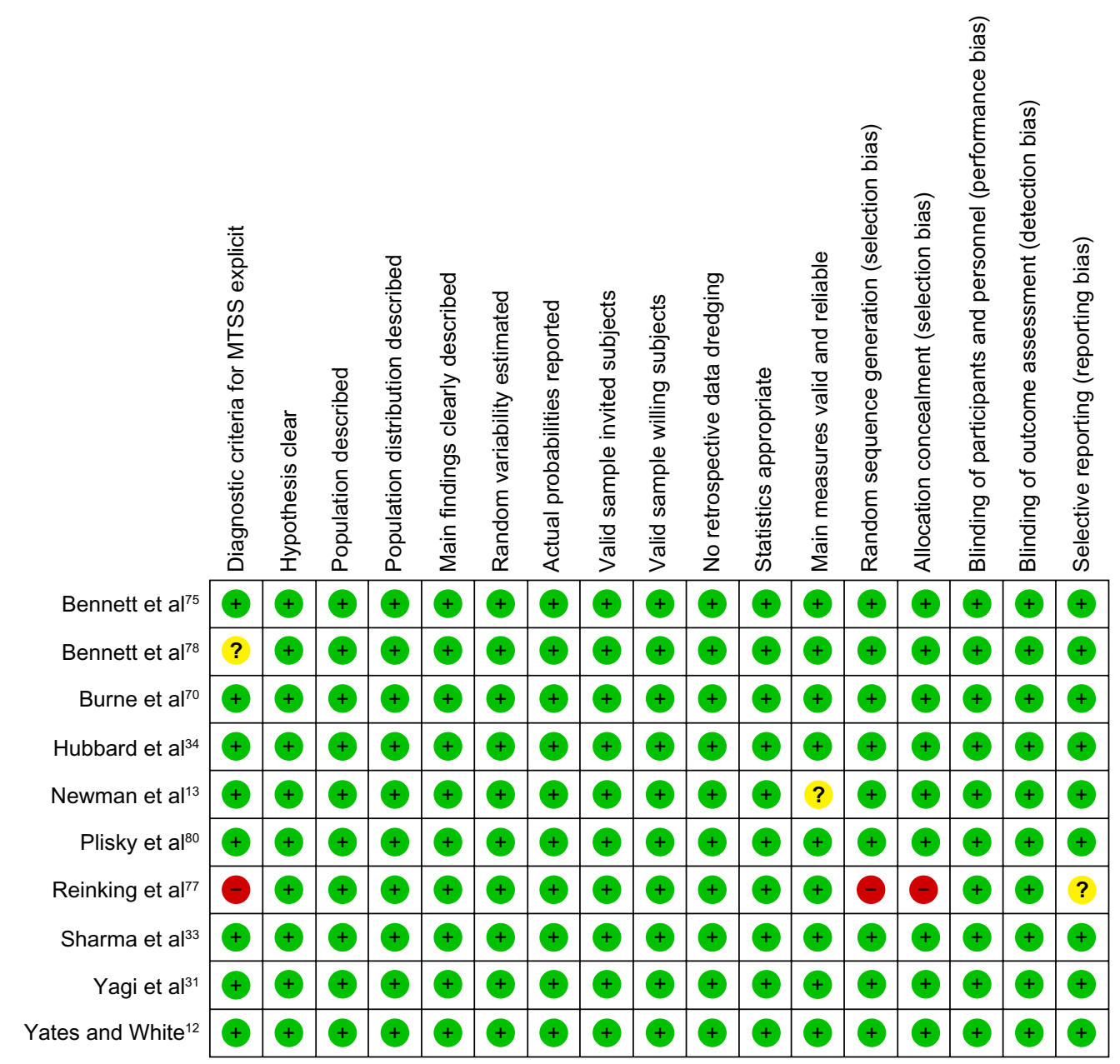

Figure 3 Risk of bias summary: reviews authors' judgments about each risk of bias item for each included study. Note: Green = low risk; yellow = unclear risk; red = high risk.

Abbreviation: MTSS, Medial tibial stress syndrome.

orthotics had a higher relative risk of developing MTSS (RR 2.31, 95\% CI 1.56-3.43, $P<0.0001$, Figure 6).

\section{Body mass index}

Five papers provided body mass index (BMI) data. In a total of 753 participants, higher BMI was significantly associated with development of MTSS (SMD 0.24, 95\% CI 0.08-0.41, $P=0.003$, Figure 7).

\section{Ankle dorsiflexion (soleus)}

Four papers investigated the relationship of dorsiflexion ROM at the ankle measured with the knee bent to diminish any effect of gastrocnemius muscle tightness. A total of 886 individuals were tested. There was no significant pooled effect relating this variable to the development of MTSS (SMD $-0.06,95 \% \mathrm{CI}-0.21$ to $0.10, P=0.48$ ).

\section{Ankle dorsiflexion (gastrocnemius)}

Five papers investigated the relationship of dorsiflexion ROM at the ankle measured with the knee straight. A total of
785 individuals were tested. Similarly, there was no significant pooled effect relating this variable to the development of MTSS (SMD $0.05,95 \% \mathrm{CI}-0.018$ to $0.28, P=0.66$ ).

\section{Running experience}

Four papers surveyed participants to establish their years of running experience. Two papers reported only dichotomized data that could not be equated for consistent analysis, leaving two papers that could be pooled for analysis. In a total group of 182 participants, there was a significant effect relating decreased running experience to the development of MTSS (SMD $-0.74,95 \% \mathrm{CI}-1.26$ to $-0.23, P=0.005$, Figure 8 ).

\section{Previous MTSS history}

Five of ten papers surveyed participants to establish if they had suffered with any previous occurrence of MTSS. In a total group of 515 participants, we found a large and significant effect relating a previous history of MTSS to repeat occurrence of MTSS (RR 3.74, 95\% CI 1.17-11.91, $P=0.03$, Figure 9). 
Table 2 Risk factors and associations with MTSS

\begin{tabular}{|c|c|c|c|c|}
\hline Outcome or subgroup & Studies & 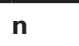 & Statistical method & Effect estimate \\
\hline Navicular drop & 4 & 565 & SMD (IV, random, 95\% Cl) & $0.26(0.02-0.50)$ \\
\hline Navicular drop $>10 \mathrm{~mm}$ & 2 & 164 & Risk ratio $(\mathrm{M}-\mathrm{H}$, fixed, $95 \% \mathrm{Cl})$ & $1.99(1.00-3.96)$ \\
\hline Foot type & 3 & 448 & Risk ratio $(\mathrm{M}-\mathrm{H}$, random, $95 \% \mathrm{Cl})$ & $1.61(0.37-6.98)$ \\
\hline Orthotic use & 3 & 403 & Risk ratio $(\mathrm{M}-\mathrm{H}$, fixed, $95 \% \mathrm{Cl})$ & $2.31(1.56-3.43)$ \\
\hline BMI & 5 & 753 & SMD (IV, fixed, 95\% Cl) & $0.24(0.08-0.4 I)$ \\
\hline BMI $<18.5$ & 3 & 257 & Risk ratio $(\mathrm{M}-\mathrm{H}$, fixed, $95 \% \mathrm{Cl})$ & $1.16(0.79-1.73)$ \\
\hline Ankle DF ROM (soleus) & 4 & 886 & SMD (IV, fixed, $95 \% \mathrm{Cl})$ & $-0.06(-0.2 \mathrm{I}-0.10)$ \\
\hline Ankle DF ROM (gastrocnemius) & 5 & 785 & SMD (IV, random, $95 \% \mathrm{Cl})$ & $0.05(-0.18$ to 0.28$)$ \\
\hline More years of running & 2 & 182 & SMD (IV, fixed, 95\% Cl) & $-0.79(-1.15,-0.44)$ \\
\hline Previous history MTSS & 5 & 515 & Risk ratio $(\mathrm{M}-\mathrm{H}$, random, $95 \% \mathrm{Cl})$ & $3.74(1.17-\mid 1.91)$ \\
\hline Female gender & 8 & 1226 & Risk ratio $(\mathrm{M}-\mathrm{H}$, random, $95 \% \mathrm{Cl})$ & $1.91(1.11-3.28)$ \\
\hline Male hip IR ROM & 2 & 268 & SMD (IV, random, 95\% Cl) & $0.36(-0.3 \mathrm{I}$ to $\mathrm{I} .03)$ \\
\hline Male hip ER ROM & 2 & 268 & SMD (IV, random, 95\% Cl) & $0.67(0.29-1.04)$ \\
\hline
\end{tabular}

Abbreviations: $\mathrm{BMI}$, body mass index; $\mathrm{Cl}$, confidence interval; $\mathrm{DF}$, dorsiflexion; $\mathrm{M}-\mathrm{H}$, Mantel Haenszel test; IR, internal rotation; ER, external rotation; ROM, range of motion; SMD, standard mean difference; MTSS, medial tibial stress syndrome; IV, inverse variance.

\section{Female gender}

Nine of ten papers involved both male and female participants. In total, 187 cases of MTSS developed in 513 females and 210 cases of MTSS developed in 957 males. Females were found to be at significantly higher risk of developing MTSS than males, at a ratio of 1.71:1 (RR 1.71, 95\% CI 1.15-2.54, $P=0.008$, Figure 10 ).

\section{Male hip external rotation}

Two papers reported male and female hip rotation ranges (internal and external) measured via goniometry. Both reported male and female data separately. Increased external rotation ROM of the hip was found to be significant only for males $(\mathrm{n}=268)$ in this meta-analysis (SMD 0.67, 95\% CI $0.29-1.04, P<0.001$, Figure 11).

\section{Discussion}

In clinical practice, multiple risk factors are seen as being linked to MTSS as a result of various research findings, or as a result of practitioners' beliefs, experiences, biases, and paradigms. Examples of the array of risk factors discussed in the literature review for this paper are provided in Table 1. The present paper provides clear evidence as to which risk factors can be most reliably linked to MTSS in runners. We propose and discuss a continuum model of pathogenesis of MTSS within the context of current evidence, clinical sequelae, related conditions, and the risk factors we have identified (Figure 12).

\section{Structural/anatomic risk factors}

Greater navicular drop is associated with an increased risk of developing MTSS. The effect size for the continuous variable is small, suggesting that the MTSS group had only a slightly increased navicular drop when compared with the uninjured group. The mean difference in navicular drop between MTSS and non-MTSS groups was $0.85 \mathrm{~mm}$, which is a difference that is almost clinically impossible to detect given that the standard error of the measure is between $1.1 \mathrm{~mm}$ and $3.0 \mathrm{~mm}$

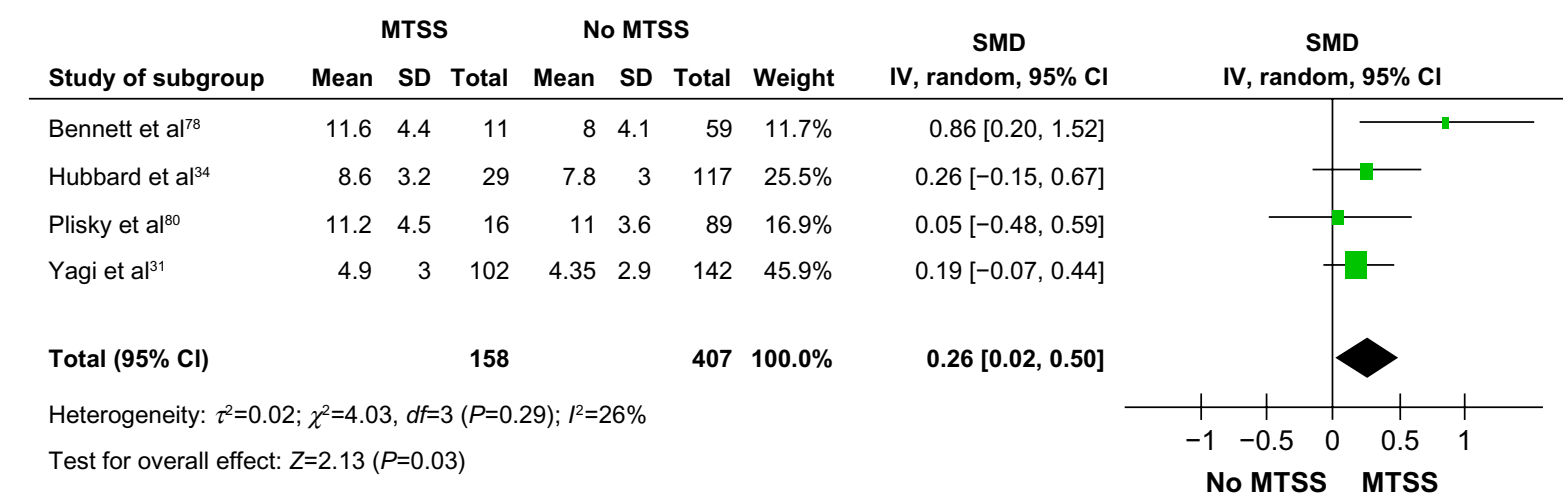

Figure 4 Forest plot of comparison: risk factors and associations with MTSS and navicular drop.

Notes: Green squares = SMD for each study, the size of the squares represent relative $n$. Black diamond $=$ pooled effect of variable.

Abbreviations: $\mathrm{Cl}$, confidence interval; MTSS, medial tibial stress syndrome; SD, standard deviation; SMD, standard mean difference; IV, inverse variance. 


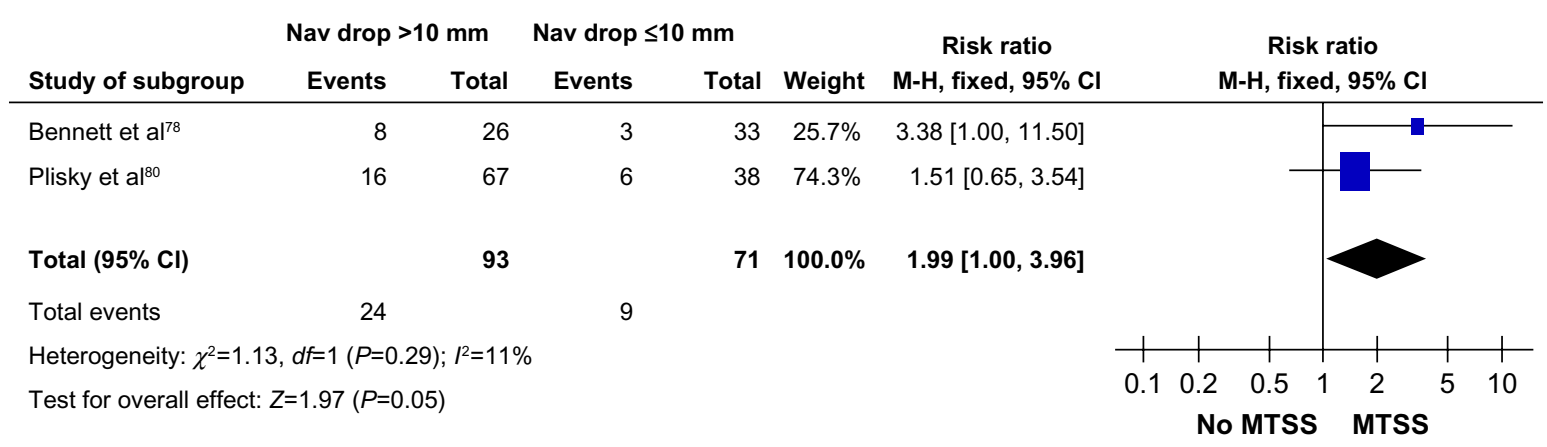

Figure 5 Forest plot of comparison: risk factors and associations with MTSS and navicular drop $>10 \mathrm{~mm}$.

Notes: Blue squares $=$ RR for each study, the size of the squares represent relative $n$. Black diamond $=$ pooled effect of variable.

Abbreviations: $\mathrm{Cl}$, confidence interval; MTSS, medial tibial stress syndrome; $\mathrm{M}-\mathrm{H}$, Mantel Haenszel test; Nav, navicular; RR, risk ratio.

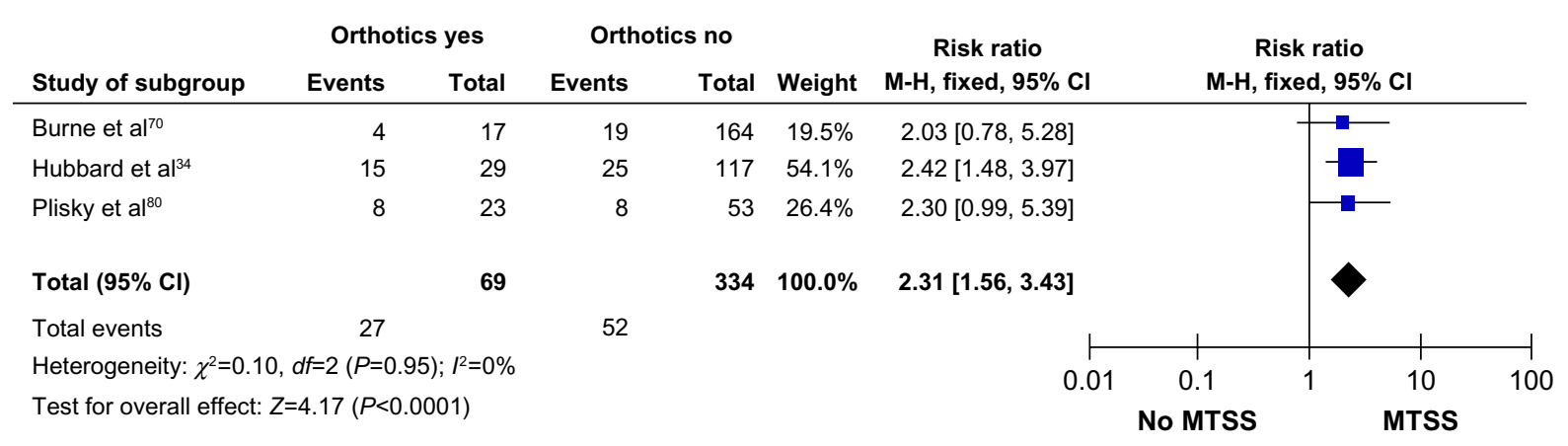

Figure 6 Forest plot of comparison: risk factors and associations with MTSS and orthotic use.

Notes: Blue squares $=$ RR for each study, the size of the squares represent relative $n$. Black diamond $=$ pooled effect of variable.

Abbreviations: $\mathrm{Cl}$, confidence interval; MTSS, medial tibial stress syndrome; $\mathrm{M}-\mathrm{H}$, Mantel Haenszel test; RR, risk ratio.

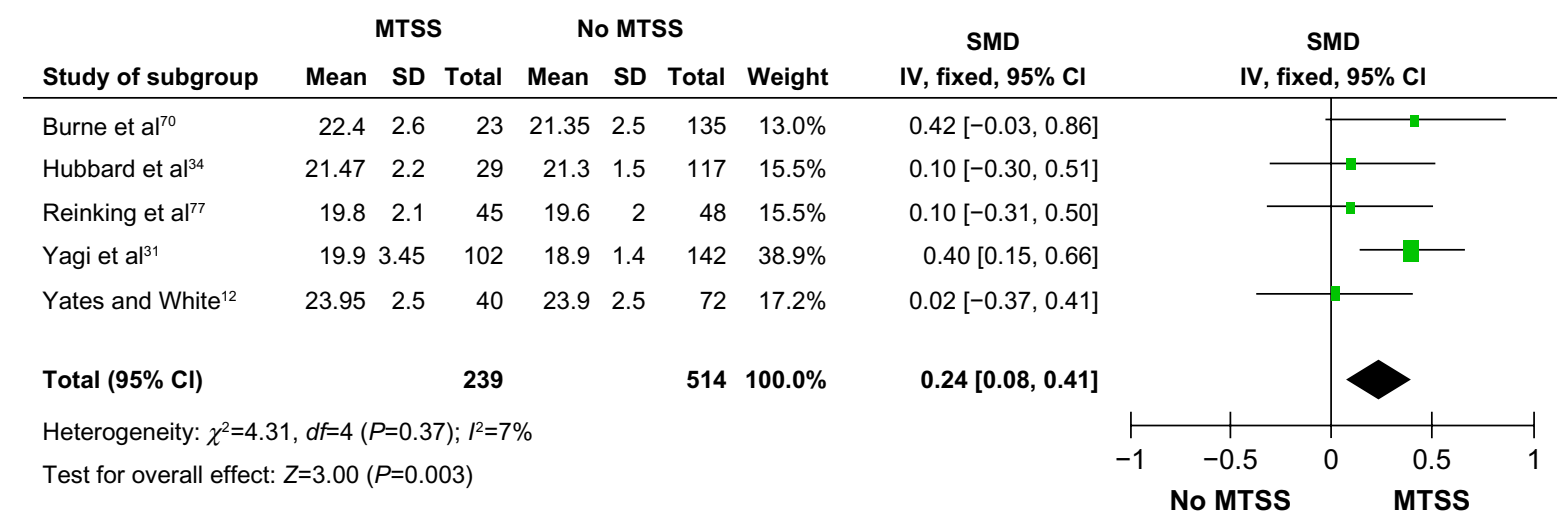

Figure 7 Forest plot of comparison: risk factors and associations with MTSS and BMI.

Notes: Green squares = SMD for each study, the size of the squares represent relative $n$. Black diamond = pooled effect of variable.

Abbreviations: BMI, body mass index; Cl, confidence interval; MTSS, medial tibial stress syndrome; SD, standard deviation; IV, inverse variance; SMD, standard mean difference.

MTSS No MTSS

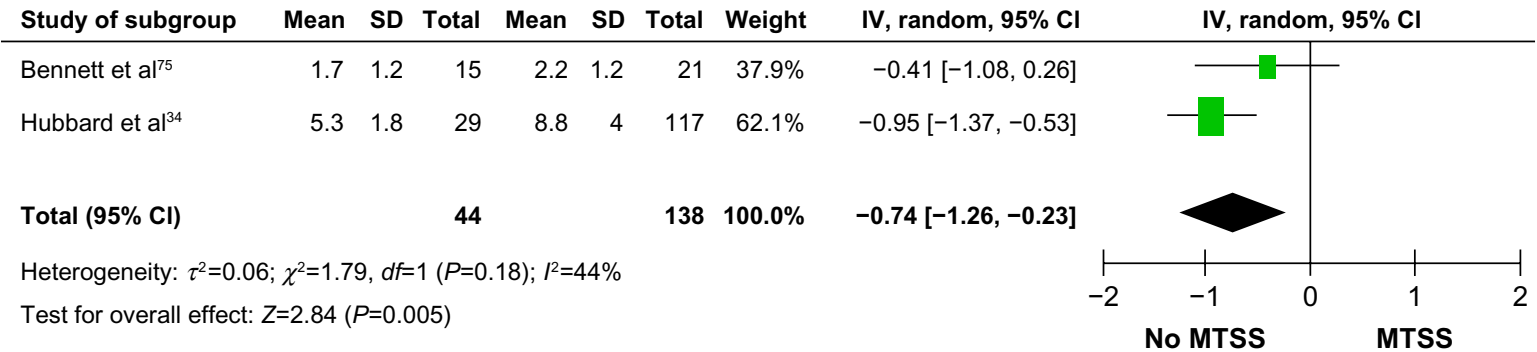

Figure 8 Forest plot of comparison: risk factors and associations with MTSS and years of running experience.

Notes: Green squares = SMD for each study, the size of the squares represent relative $n$. Black diamond $=$ pooled effect of variable.

Abbreviations: $\mathrm{Cl}$, confidence interval; MTSS, medial tibial stress syndrome; SD, standard deviation; SMD, standard mean difference; IV, inverse variance. 


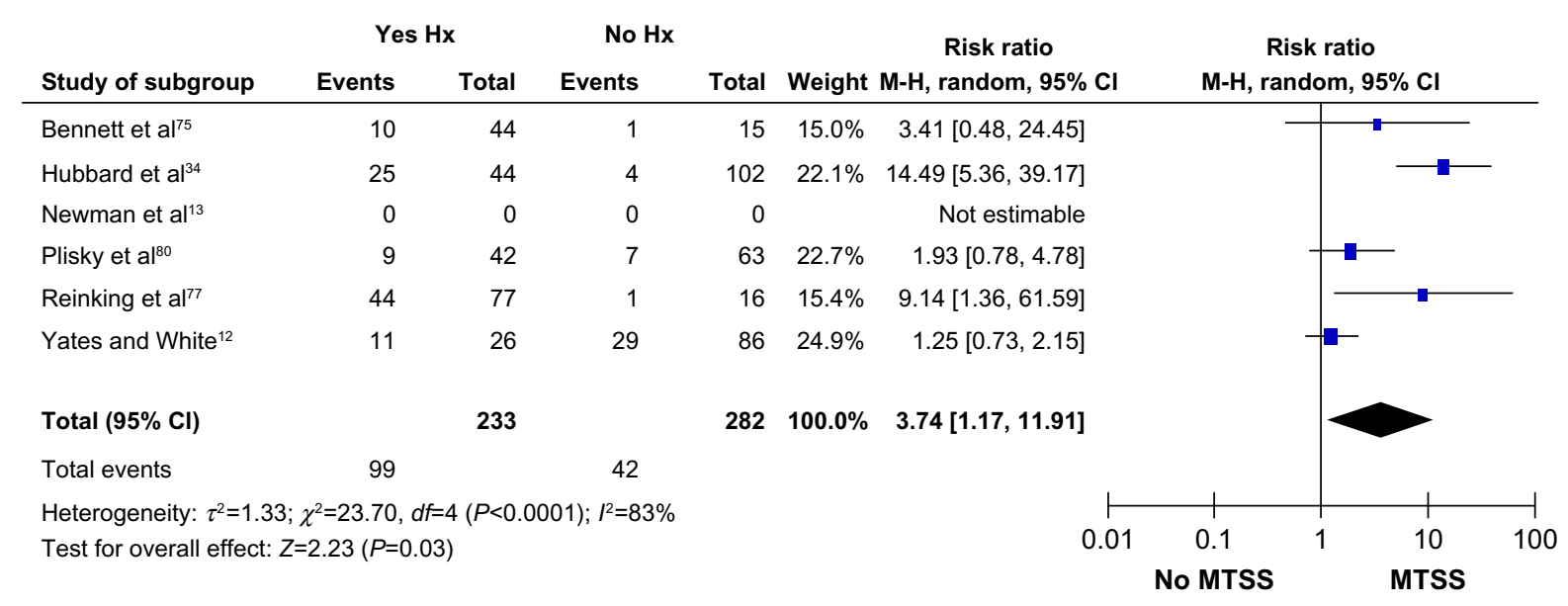

Figure 9 Forest plot of comparison: risk factors and associations with MTSS and previous history of MTSS.

Notes: Blue squares $=$ RR for each study, the size of the squares represent relative $n$. Black diamond $=$ pooled effect of variable.

Abbreviations: $\mathrm{Cl}$, confidence interval; MTSS, medial tibial stress syndrome; M-H, Mantel Haenszel test; Hx, previous history of MTSS; RR, risk ratio.

(intraclass correlation coefficient 0.84$)^{31,34}$ The standard error of the measure is the standard deviation of the measureremeasure difference distribution, and therefore reflects the kinds of differences that might arise from measurement error alone. There were some differences in how the reviewed papers measured navicular drop. Whilst these differences in methodology introduce variance, ${ }^{35}$ the fact that the metaanalysis still returns a significant finding emphasizes the importance of the measurement.

It is likely that differences in measurement technique are important, particularly when determining clinically relevant cutoff values. Notably, the tandem stance technique appears to yield much smaller differences in navicular height. When the dichotomous variable, navicular drop greater than $10 \mathrm{~mm}$, was analyzed, the effect size improved to within the moderate range. Classification of individuals who are at risk of developing MTSS using this cutoff point is a much more useful clinical tool, and one that can be used with confidence.

Pronated foot type and dynamic overpronation have long been thought to contribute to higher loads in the kinetic chain and therefore to higher rates of injury. ${ }^{36}$ Various kinematic analyses have investigated lower limb loads, in association with pronation rate and amplitudes with various results that are beyond the scope of this paper. ${ }^{35,37-39}$ Irrespective of the consensus or otherwise of these papers, pronated foot type was not found to be associated with MTSS in this meta-analysis. Whilst the navicular drop test and the Foot Posture Index have demonstrated good intertest reliability independently of each other, ${ }^{40,41}$ the correlation between these two methods has not been established. Both are measures of pronation, but only navicular drop appears to be a useful predictor in MTSS. It may be important that the medial

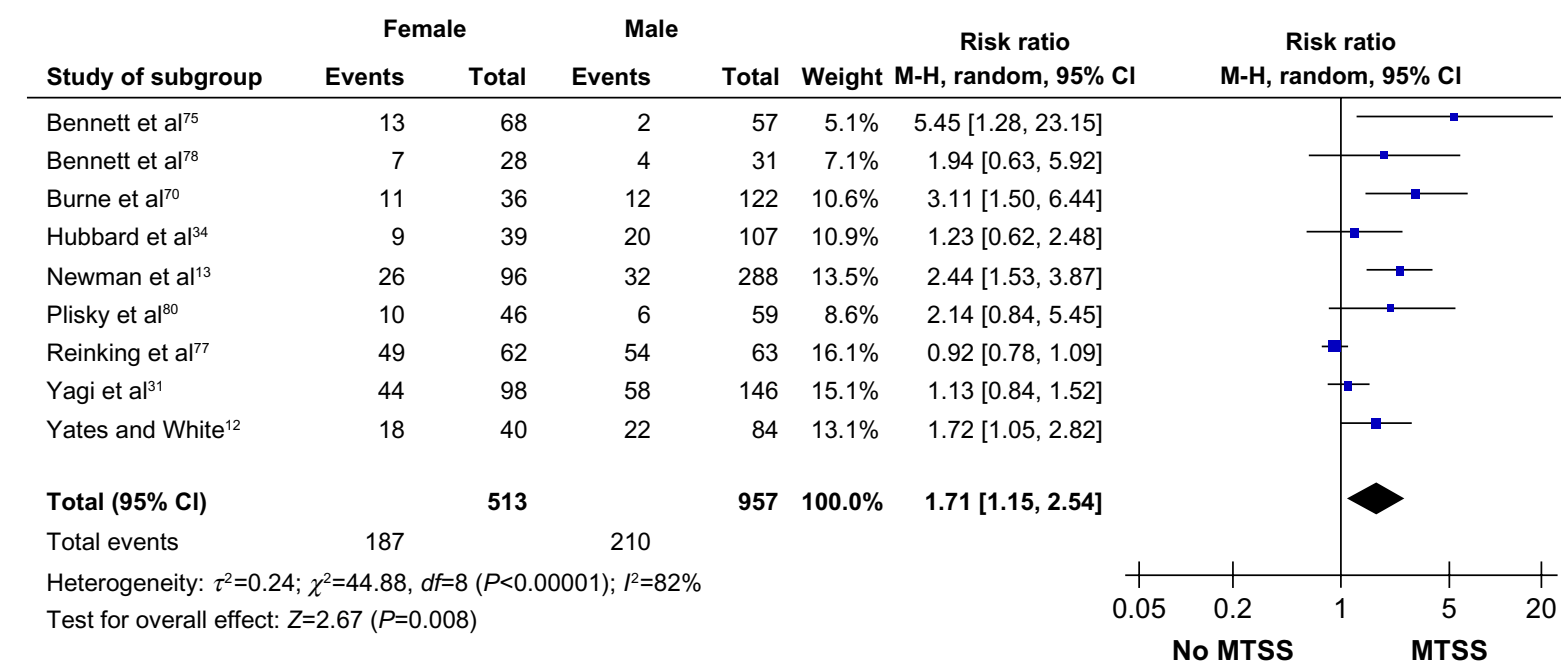

Figure 10 Forest plot of comparison: risk factors and associations with MTSS and female gender.

Notes: Blue squares $=$ RR for each study, the size of the squares represent relative $n$. Black diamond $=$ pooled effect of variable.

Abbreviations: $\mathrm{Cl}$, confidence interval; MTSS, medial tibial stress syndrome; $\mathrm{M}-\mathrm{H}$, Mantel Haenszel test; RR, risk ratio. 


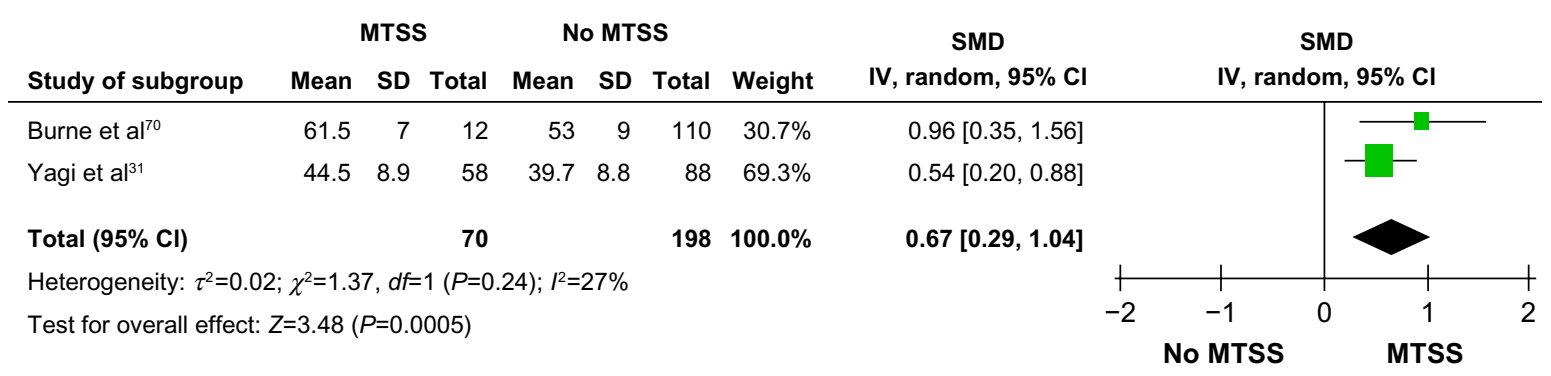

Figure I I Forest plot of comparison: risk factors and associations with MTSS and male hip external rotation ROM.

Notes: Green squares = SMD for each study, the size of the squares represent relative $n$. Black diamond = pooled effect of variable.

Abbreviations: $\mathrm{Cl}$, confidence interval; MTSS, medial tibial stress syndrome; SD, standard deviation; ROM, range of motion; IV, inverse variance; SMD, standard mean difference.

longitudinal arch control systems, both passive and active, need to be isolated from calcaneal and subtalar systems to enable further understanding of these relationships. ${ }^{35,42-45}$

Increased BMI was significantly associated with development of MTSS. However, the effect size was small. This finding could mean that the heavier impact loads that are likely to be associated with increased BMI are a factor, or that deconditioning plays a part. Fitness data for these participants were not included in the papers, but would be a useful addition to further studies in this area. The mean BMI values in these papers and the ranges, where reported, do not suggest that these participants were anything but within the normal range. Further investigation of fitness, bone/fat/ muscle ratios, and MTSS prevalence is needed. Low BMI of $<18.5$ was not found to be a significant risk factor for MTSS in this meta-analysis.

Increased or decreased range of motion of dorsiflexion can be confidently ruled out as a risk factor for the development of MTSS. While tightness of plantar flexors is often a feature of MTSS sufferers, it is likely an effect of the condition and not a cause. Stretching of gastrocnemius and soleus is commonly advised for runners to avoid injury, because improvements in range of motion at the ankle are thought to assist the absorption of impact loads. Whether stretching is useful in either the treatment or prevention of MTSS is beyond the scope of this paper.

\section{Historical risk factors}

Fewer years of running experience was significantly related to the development of MTSS. Conditioning of neuromuscular and bone adaptation systems is clearly important within current understanding about the pathology of MTSS..$^{42,46-49}$ Previous studies have shown that the recovery time from MTSS is generally long. This is best illustrated in a randomized controlled trial by Moen et al, which revealed that recovery to the level of presymptomatic running volumes took 6-10 months for the majority of sufferers. ${ }^{23}$ Determination of cutoff values for running experience and MTSS risk are needed for further clarification. The effect of preconditioning programs for reducing injury in runners has not yet been

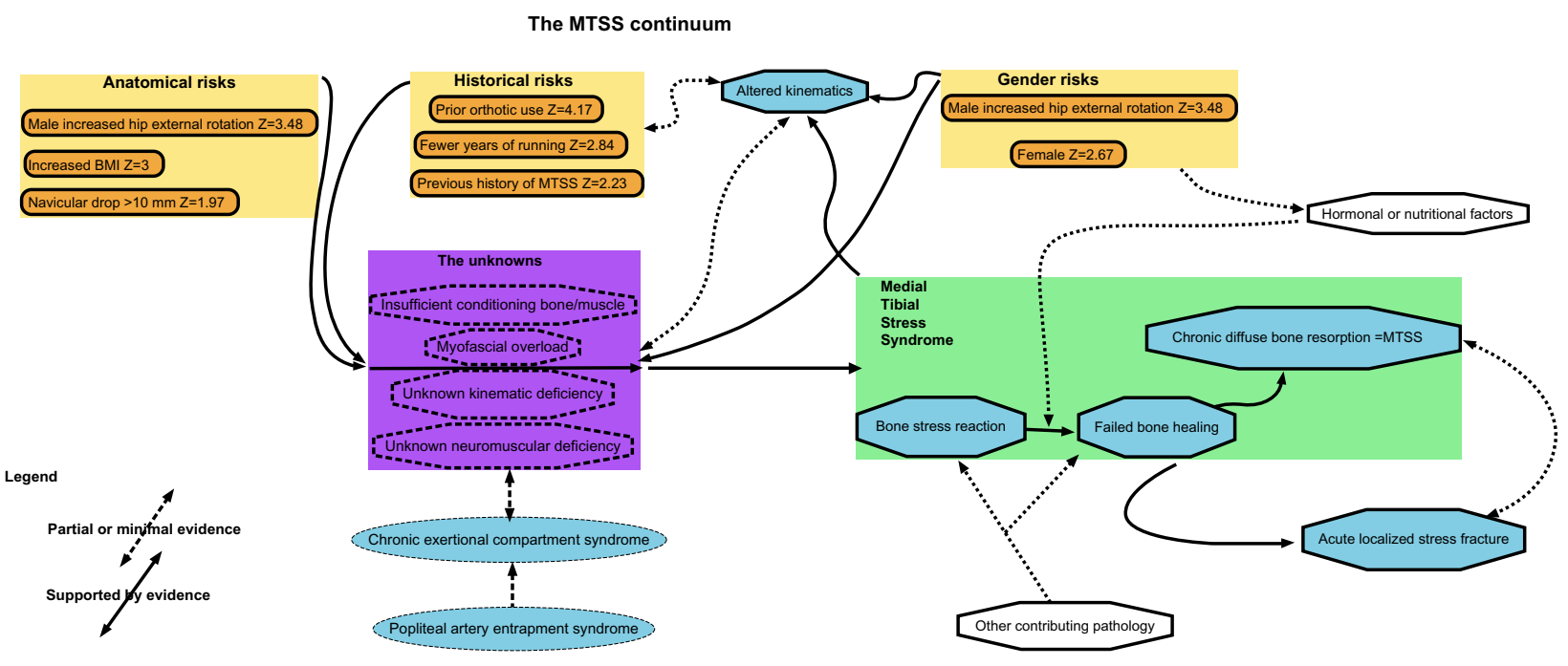

Figure 12 Proposed continuum model of pathogenesis of MTSS.

Abbreviations: BMI, body mass index; MTSS, medial tibial stress syndrome. 
established; however, a randomized controlled trial has shown that a 4 -week program is insufficient. ${ }^{50}$ Data on the volume and intensity of training, and the nature of training surface, also need to be gathered as qualifiers to help understand what constitutes an optimal time for positive adaptation. This risk factor is probably the most modifiable and therefore the most important to investigate and understand in more detail. Standardization of data is important here and should include frequency, distance, and speed as a minimum for future comparisons. ${ }^{51}$

Prior use of orthotics was found to be a highly significant risk factor for developing MTSS. The effect size was large. Examining the relationship between orthotic use and subsequent development of MTSS necessitates consideration of what orthotics do. Kinematic effects, ${ }^{52}$ neuromuscular pattern effects, ${ }^{46,53,54}$ and shock attenuation effects ${ }^{44,55}$ of orthotics are not well understood. Orthotics are commonly prescribed to correct or support a foot that has been deemed to be in less than optimal alignment, but their role in prevention and intervention is unclear according to a recent systematic review. ${ }^{56}$ Our analysis suggests their use is a causative risk factor and therefore they are not useful for prevention. The mechanism of this effect is unclear. It could be a result of deconditioning of the lower limb or foot musculature, but no study has detected weakness or lack of muscular endurance to be a risk. If orthotics have a shock attenuation effect, it may be that the tibial bone is not loaded sufficiently for adequate adaptation to occur. At least $25 \%$ of the participants included in this meta-analysis had been prescribed orthotics prior to developing MTSS. The orthotic materials, designs, and nature of corrections are not specified in the papers used for the current analysis. A recent systematic review with metaanalysis ${ }^{54}$ highlights the complexity and variability of orthotic effects in the domains of shock attenuation, kinematics, and neuromuscular control. Design and material properties, as well as history of injury, will influence the effect of orthotics. For example, Mills et al found that in uninjured subjects, only a posted-molded orthotic had a positive shock attenuation effect. ${ }^{54}$ Peak rearfoot eversion was reduced by orthotics, but only if the orthotics were nonmolded and only in uninjured subjects. Further, orthotic use was associated with increases in electromyographic activity of tibialis anterior and peroneus longus by between $19 \%$ and $37 \%$ of maximal voluntary contraction with no increase in soleus or tibialis posterior activity, but these effects were different depending on injury status. Without knowledge of orthotic types involved in each of the meta-analysis papers, application of these findings to the present study is not possible.
There was a large and significant effect linking a previous history of MTSS to the development of repeat occurrence of MTSS. Either the causes of MTSS are persistent because they are intrinsic, or the effects of MTSS are resistant to change. Magnusson et al found residual evidence of bony demineralization in MTSS sufferers for up to 8 years after an episode. ${ }^{15}$ Myofascial structures tend to heal more rapidly than bone or entheses ${ }^{57,58}$ and this lends weight to the theory of failed bone healing in MTSS. This is a nonmodifiable risk factor that endorses the need to focus on strategies to prevent MTSS from developing.

\section{Gender-related risk factors}

The risk factors for developing MTSS have previously been shown to differ between genders. ${ }^{59}$ In this paper, increased external rotation ROM of the hip was found to be a significant predictor of MTSS, but only in males. Both of the relevant papers in this analysis used passive hip ROM measures with the hip in 90 degrees of hip flexion. It is currently unclear how motion measured in this way is related to running postures. There are known and significant differences between both active and passive external rotation ROM measures taken at 90 degrees of hip flexion versus those taken at 0 degrees flexion. ${ }^{60-63}$ There is no reported consistent difference in hip external rotation ROM between males and females; however, earlier lumbopelvic movement in men when performed actively has been identified. ${ }^{64}$ It is possible that the passive ROM of hip external rotation may lead to an altered movement pattern in running that is specific to males. Hip muscle activation patterns have been found to influence impact loads distally. ${ }^{65}$

Females are at significantly greater risk of developing MTSS than males. A number of studies have investigated gender-related differences in running kinematics. ${ }^{63,66}$ These studies have shown female runners to have greater knee abduction at heel contact, decreased knee flexion, increased peak internal rotation of the hip, and increased femoral adduction. These variables appear to fit a pattern associated with MTSS sufferers as well as anterior cruciate ligament injury and patellofemoral pain syndrome, but none of these variables were able to be included in this meta-analysis. ${ }^{37}$ Kinematics may also be influenced by hormonal status and phase ${ }^{67}$ Further studies need to investigate female kinematics prospectively for an association with MTSS and to incorporate gender as a covariate in the study design.

Female athletes typically have later onset of menarche, and female runners suffer more commonly from menstrual disturbance than the general population. The latter feature has been associated with lower bone mineral density ${ }^{68}$ but 
not consistently in the tibia. It is possible that female runners are at risk of MTSS if they are starting from a lower base amount of bone density. Bennell et al, in a prospective study of 53 female athletes, found age of menarche, menstrual disturbance, lower bone mineral density, leg length discrepancy, less lean mass of the shank, and a lower fat diet were significant risk factors for stress fracture in females. None of these risk factors were predictive in males. ${ }^{69}$ Further prospective analysis of these risk factors in females who develop MTSS is warranted.

\section{Continuum theory of pathogenesis of MTSS}

The factors addressed in this review can be linked in a model that combines the factors with processes that represent a continuum of increasing risk of developing MTSS (Figure 12). Many of these processes ("the unknowns") are yet to be supported by prospective evidence. The mechanism by which these risk factors influence the development of MTSS remains unclear.

Cohort studies have identified altered kinematics in MTSS sufferers, which may partly explain the link between previous history of MTSS and future MTSS, but to date no prospective trial has identified a specific kinematic risk factor.

The contributions and interrelationships between popliteal artery entrapment syndrome, chronic exertional compartment syndrome, stress fracture, and MTSS are also unclear, yet clinically they can coexist. This model may provide a visual representation of where further research may focus.

\section{Conclusion}

Female gender, a previous history of MTSS, fewer years of running experience, orthotic use, increased BMI, an increased navicular drop, and increased external rotation hip ROM in males are all significantly associated with an increased risk of developing MTSS in runners. The mechanism by which these risk factors influence the development of MTSS remains unclear.

\section{Implications for practice}

Runners who have combinations of risk factors identified in this paper should be advised to minimize their total impact loads whilst attempting to modify their risk. For example, a runner with a history of MTSS and who has navicular drop $>10 \mathrm{~mm}$ should be closely monitored in building their running, until they have survived long enough to have a "low-risk" volume of running established. This precaution is enhanced if they are female or have high hip external rotation range as a male.

\section{Implications for research}

The suite of variables identified in this review needs to be tested in a prospective trial to see if the calculated risks are confirmed. A large field study of these variables is needed to build a predictive model and algorithm, and to establish cutoff values for the various factors. Future studies should analyze males and females separately, given that risk factors vary by gender.

\section{Author contributions}

Phil Newman performed the review and undertook the main write up, Jeremy Witchalls assisted with design and analysis, and Gordon Waddington and Roger Adams assisted with design. All authors were involved in drafting the article or revising it critically for important intellectual content.

\section{Disclosure}

The authors report no conflicts of interest in this work.

\section{References}

1. Detmer DE. Chronic shin splints: classification and management of medial tibial stress syndrome. Sports Med. 1986;3(6):436-446.

2. Andrish JT, Bergfeld JA, Walheim J. A prospective study on the management of shin splints. J Bone Joint Surg Am. 1974;56(8): $1697-1700$.

3. Vicente JS, Grande ML, Torre JR, et al. "Shin splint" syndrome and tibial stress fracture in the same patient diagnosed by means of $99 \mathrm{mTc}-$ HMDP SPECT/CT. Clin Nucl Med. 2013;38(4):e178-e181.

4. Mubarak SJ, Gould RN, Lee YF, Schmidt DA, Hargens AR. The medial tibial stress syndrome a cause of shin splints. Am J Sports Med. 1982;10(4):201-205.

5. Michael RH, Holder LE. The soleus syndrome. A cause of medial tibial stress (shin splints). Am J Sports Med. 1985;13(2):87-94.

6. Bhatt R, Lauder I, Finlay DB, Allen MJ, Belton IP. Correlation of bone scintigraphy and histological findings in medial tibial syndrome. $\mathrm{Br} \mathrm{J}$ Sports Med. 2000;34(1):49-53.

7. Johnell O, Rausing A, Wendeberg B, Westlin N. Morphological changes in shin splints. Clin Orthop Relat Res. 1982;(167):180-184.

8. Stickley CD, Hetzler RK, Kimura IF, Lozanoff S. Crural fascia and muscle origins related to medial tibial stress syndrome symptom location. Med Sci Sports Exerc. 2009;41(11):1991-1996.

9. Saxena A, O'Brien T, Bunce D. Anatomic dissection of the tibialis posterior muscle and its correlation to medial tibial stress syndrome. J Foot Surg. 1990;29(2):105-108.

10. Bouché RT, Johnson CH. Medial tibial stress syndrome (tibial fasciitis). J Am Podiatr Med Assoc. 2007;97(1):31-36.

11. Beck BR, Osternig LR. Medial tibial stress syndrome. The location of muscles in the leg in relation to symptoms. J Bone Joint Surg Am. 1994;76(7):1057-1061.

12. Yates B, White $\mathrm{S}$. The incidence and risk factors in the development of medial tibial stress syndrome among naval recruits. Am J Sports Med. 2004;32(3):772-780.

13. Newman P, Adams R, Waddington G. Two simple clinical tests for predicting onset of medial tibial stress syndrome: shin palpation test and shin oedema test. Br J Sports Med. 2012;46(12):861-864. 
14. Beck BR. Tibial stress injuries: an aetiological review for the purposes of guiding management. Sports Med. 1998;26(4):265-279.

15. Magnusson HI, Ahlborg HG, Karlsson C, Nyquist F, Karlsson MK. Low regional tibial bone density in athletes with medial tibial stress syndrome normalizes after recovery from symptoms. Am J Sports Med. 2003;31(4):596-600.

16. Magnusson HI, Westlin NE, NyqvistF, Gärdsell P, Seeman E, Karlsson MK. Abnormally decreased regional bone density in athletes with medial tibial stress syndrome. Am J Sports Med. 2001;29(6):712-715.

17. Batt ME, Ugalde V, Anderson MW, Shelton DK. A prospective controlled study of diagnostic imaging for acute shin splints. Med Sci Sports Exerc. 1998;30(11):1564-1571.

18. Fredericson M, Bergman AG, Hoffman KL, Dillingham MS. Tibial stress reaction in runners correlation of clinical symptoms and scintigraphy with a new magnetic resonance imaging grading system. Am J Sports Med. 1995;23(4):472-481.

19. Gaeta M, Minutoli F, Scribano E, et al. CT and MR imaging findings in athletes with early tibial stress injuries: comparison with bone scintigraphy findings and emphasis on cortical abnormalities. Radiology. 2005;235(2):553-561.

20. Moen MH, Tol JL, Weir A, Steunebrink M, De Winter TC. Medial tibial stress syndrome: a critical review. Sports Med. 2009;39(7):523-546.

21. Magnusson HI, Ahlborg HG, Karlsson C, Nyquist F, Karlsson MK. Tibial bone density in athletes with medial tibial stress syndrome: a controlled study. Am J Sports Med. 2003;31(4):596-600.

22. Moen MH, Schmikli SL, Weir A, et al. A prospective study on MRI findings and prognostic factors in athletes with MTSS. Scand J Med Sci Sports. April 20, 2012. [Epub ahead of print.]

23. Moen MH, Holtslag L, Bakker E, et al.The treatment of medial tibial stress syndrome in athletes; a randomized clinical trial. Sports Med Arthrosc Rehabil Ther Technol. 2012;4:12.

24. Craig DI. Medial tibial stress syndrome: evidence-based prevention. J Athl Train. 2008;43(3):316-318.

25. Thacker SB, Gilchrist J, Stroup DF, Kimsey CD. The prevention of shin splints in sports: a systematic review of literature. Med Sci Sports Exerc. 2002;34(1):32-40.

26. Downs SH, Black N. The feasibility of creating a checklist for the assessment of the methodological quality both of randomised and nonrandomised studies of health care interventions. J Epidemiol Community Health. 1998;52(6):377-384.

27. Huedo-Medina T, Sanchez-Meca J, Marin-Martinez F, Botella J. Assessing heterogeneity in meta-analysis: Q statistic or I2 index? CHIP Documents. Available from: http://digitalcommons.uconn.edu/ chip_docs/19. Accessed September 10, 2013.

28. Hopkins WG. A scale of magnitudes for effect statistics. Available from: http://www.sportsci.org/resource/stats/index.html. Accessed September 10, 2013.

29. Brody D. Techniques in the evaluation and treatment of the injured runner. Orthop Clin North Am. 1982;13(3):541-558.

30. Buchanan KR, Davis I. The relationship between forefoot, midfoot, and rearfoot static alignment in pain-free individuals. J Orthop Sports Phys Ther. 2005;35(9):559-566.

31. Yagi S, Muneta T, Sekiya I. Incidence and risk factors for medial tibial stress syndrome and tibial stress fracture in high school runners. Knee Surg Sports Traumatol Arthrosc. 2013;21(3):556-563.

32. Redmond AC, Crosbie J, Ouvrier RA. Development and validation of a novel rating system for scoring standing foot posture: the Foot Posture Index. Clin Biomech (Bristol, Avon). 2006;21(1):89-98.

33. Sharma J, Golby J, Greeves J, Spears IR. Biomechanical and lifestyle risk factors for medial tibia stress syndrome in army recruits: a prospective study. Gait Posture. 2011;33(3):361-365.

34. Hubbard TJ, Carpenter EM, Cordova ML. Contributing factors to medial tibial stress syndrome: a prospective investigation. Med Sci Sports Exerc. 2009;41(3):490-496.

35. Lee SY, Hertel J. Arch height and maximum rearfoot eversion during jogging in 2 static neutral positions. J Athl Train. 2012;47(1): 83-90.
36. Bates P. Shin splints - a literature review. Br J Sports Med. 1985;19(3): 132-137.

37. Loudon JK, Reiman MP. Lower extremity kinematics in running athletes with and without a history of medial shin pain. Int $J$ Sports Phys Ther. 2012;7(4):356-364.

38. Lee SY. Direct and indirect effects of alignment, range of motion, and gait measures on medial tibial stress syndrome status of runners [dissertation]. Charlottesville: University of Virginia; 2009.

39. Raissi GR, Cherati AD, Mansoori KD, Razi MD. The relationship between lower extremity alignment and medial tibial stress syndrome among non-professional athletes. Sports Med Arthrosc Rehabil Ther Technol. 2009;1(1):11.

40. Cornwall MW, McPoil TG, Lebec M, Vicenzino B, Wilson J. Reliability of the Modified Foot Posture Index. $J$ Am Podiatr Med Assoc. 2008;98(1):7-13.

41. Picciano AM, Rowlands MS, Worrell T. Reliability of open and closed kinetic chain subtalar joint neutral positions and navicular drop test. J Orthop Sports Phys Ther. 1993;18(4):553-558.

42. Rathleff MS, Samani A, Olesen CG, Kersting UG, Madeleine P. Inverse relationship between the complexity of midfoot kinematics and muscle activation in patients with medial tibial stress syndrome. J Electromyogr Kinesiol. 2011;21(4):638-644.

43. Billis E, Katsakiori E, Kapodistrias C, Kapreli E. Assessment of foot posture: correlation between different clinical techniques. The Foot. 2007;17(2):65-72.

44. Hargrave MD, Carcia CR, Gansneder BM, Shultz SJ. Subtalar pronation does not influence impact forces or rate of loading during a single-leg landing. J Athl Train. 2003;38(1):18-23.

45. Bandholm T, Boysen L, Haugaard S, Zebis MK, Bencke J. Foot medial longitudinal-arch deformation during quiet standing and gait in subjects with medial tibial stress syndrome. $J$ Foot Ankle Surg. 2008;47(2):89-95.

46. Newsham KR, Beekley MD, Lauber CA. A neuromuscular intervention for exercise-related medial leg pain. J Sport Rehabil. 2012;21(1):54-62.

47. Franettovich M, Chapman AR, Blanch P, Vicenzino B. Altered neuromuscular control in individuals with exercise-related leg pain. Med Sci Sports Exerc. 2010;42(3):546-555.

48. Franklyn M, Oakes B, Field B, Wells P, Morgan D. Section modulus is the optimum geometric predictor for stress fractures and medial tibial stress syndrome in both male and female athletes. Am J Sports Med. 2008;36(6):1179-1189.

49. Yeung EW, Yeung SS. A systematic review of interventions to prevent lower limb soft tissue running injuries. Br J Sports Med. 2001;35(6):383-389.

50. Bredeweg SW, Zijlstra S, Bessem B, Buist I. The effectiveness of a preconditioning programme on preventing running-related injuries in novice runners: a randomised controlled trial. Br J Sports Med. 2012;46(12):865-870.

51. Nielsen RO, Buist I, Sørensen H, Lind M, Rasmussen S. Training errors and running related injuries: a systematic review. Int $J$ Sports Phys Ther. 2012;7(1):58-75.

52. Abdallah AA, Radwan AY. Biomechanical changes accompanying unilateral and bilateral use of laterally wedged insoles with medial arch supports in patients with medial knee osteoarthritis. Clin Biomech (Bristol, Avon). 2011;26(7):783-789.

53. Garth WP Jr, Miller ST. Evaluation of claw toe deformity, weakness of the foot intrinsics, and posteromedial shin pain. Am J Sports Med. 1989;17(6):821-827.

54. Mills K, Blanch P, Chapman AR, McPoil TG, Vicenzino B. Foot orthoses and gait: a systematic review and meta-analysis of literature pertaining to potential mechanisms. Br J Sports Med. 2010;44(14):1035-1046.

55. McMillan A, Payne C. Effect of foot orthoses on lower extremity kinetics during running: a systematic literature review. $J$ Foot Ankle Res. 2008;1(1):13.

56. Richter RR, Austin TM, Reinking MF. Foot orthoses in lower limb overuse conditions: a systematic review and meta-analysis-critical appraisal and commentary. J Athl Train. 2011;46(1):103-106. 
57. Menetrey J, Kasemkijwattana C, Day CS, et al. Growth factors improve muscle healing in vivo. J Bone Joint Surg Br. 2000;82(1):131-137.

58. Bailón-Plaza A, van der Meulen MC. Beneficial effects of moderate, early loading and adverse effects of delayed or excessive loading on bone healing. J Biomech. 2003;36(8):1069-1077.

59. Buist I, Bredeweg SW, Lemmink KA, van Mechelen W, Diercks RL. Predictors of running-related injuries in novice runners enrolled in a systematic training program a prospective cohort study. Am J Sports Med. 2010;38(2):273-280.

60. Simoneau GG, Hoenig KJ, Lepley JE, Papanek PE. Influence of hip position and gender on active hip internal and external rotation. J Orthop Sports Phys Ther. 1998;28(3):158-164.

61. Luttgens K, Hamilton N. Kinesiology: Scientific Basis of Human Motion. Madison, WI: Brown and Benchmark; 1997.

62. Ellison JB, Rose SJ, Sahrmann SA. Patterns of hip rotation range of motion: a comparison between healthy subjects and patients with low back pain. Phys Ther. 1990;70(9):537-541.

63. Ferber R, Davis IM, Williams DS 3rd. Gender differences in lower extremity mechanics during running. Clin Biomech (Bristol, Avon). 2003;18(4):350-357.

64. Gombatto SP, Collins DR, Sahrmann SA, Engsberg JR, Van Dillen LR. Gender differences in pattern of hip and lumbopelvic rotation in people with low back pain. Clin Biomech (Bristol, Avon). 2006;21(3): 263-271.

65. Ferber R, Hreljac A, Kendall KD. Suspected mechanisms in the cause of overuse running injuries: a clinical review. Sports Health. 2009;1(3):242-246.

66. Chumanov ES, Wall-Scheffler C, Heiderscheit BC. Gender differences in walking and running on level and inclined surfaces. Clin Biomech (Bristol, Avon). 2008;23(10):1260-1268.

67. Park SK, Stefanyshyn DJ, Ramage B, Hart DA, Ronsky JL. Relationship between knee joint laxity and knee joint mechanics during the menstrual cycle. Br J Sports Med. 2009;43(3):174-179.

68. Khan K, McKay H, Kannus P, Bailey D, Wark J, Benne K, editors. Physical Activity and Bone Health. Champaign, IL: Human Kinetics; 2001.
69. Bennell KL, Malcolm SA, Thomas SA, et al. Risk factors for stress fractures in track and field athletes: a twelve-month prospective study. Am J Sports Med. 1996;24(6):810-818.

70. Burne SG, Khan KM, Boudville PB, et al. Risk factors associated with exertional medial tibial pain: a 12 month prospective clinical study. Br J Sports Med. 2004;38(4):441-445.

71. Lun V, Meeuwisse WH, Stergiou P, Stefanyshyn D. Relation between running injury and static lower limb alignment in recreational runners. Br J Sports Med. 2004;38(5):576-580.

72. Willems TM, De Clercq D, Delbaere K, Vanderstraeten G, De Cock A, Witvrouw E. A prospective study of gait related risk factors for exerciserelated lower leg pain. Gait Posture. 2006;23(1):91-98.

73. Moen MH, Bongers T, Bakker EW, et al. Risk factors and prognostic indicators for medial tibial stress syndrome. Scand J Med Sci Sports. 2012;22(1):34-39.

74. Bartosik KE, Sitler M, Hillstrom HJ, Palamarchuk H, Huxel K, Kim E. Anatomical and biomechanical assessments of medial tibial stress syndrome. J Am Podiatr Med Assoc. 2010;100(2):121-132.

75. Bennett JE, Reinking MF, Pluemer B, Pentel A, Seaton M, Killian C. Factors contributing to the development of medial tibial stress syndrome in high school runners. J Orthop Sports Phys Ther. 2001;31(9): 504-510.

76. Wen DY, Puffer JC, Schmalzried TP. Injuries in runners: a prospective study of alignment. Clin J Sport Med. 1998;8(3):187-194.

77. Reinking MF, Austin TM, Hayes AM. Risk factors for self-reported exercise-related leg pain in high school cross-country athletes. $J$ Athl Train. 2010;45(1):51-57.

78. Bennett JE, Reinking MF, Rauh MJ. The relationship between isotonic plantar flexor endurance, navicular drop, and exercise-related leg pain in a cohort of collegiate cross-country runners. Int J Sports Phys Ther. 2012;7(3):267-278.

79. Pohl MB, Rabbito M, Ferber R. The role of tibialis posterior fatigue on foot kinematics during walking. J Foot Ankle Res. 2010;3:6.

80. Plisky MS, Rauh MJ, Heiderscheit B, Underwood FB, Tank RT. Medial tibial stress syndrome in high school cross-country runners: incidence and risk factors. J Orthop Sports Phys Ther. 2007;37(2):40-47.
Open Access Journal of Sports Medicine

\section{Publish your work in this journal}

Open Access Journal of Sports Medicine is an international, peer-reviewed, open access journal publishing original research, reports, reviews and commentaries on all areas of sports medicine. The manuscript management system is completely online and includes a very quick and fair peer-review system.

\section{Dovepress}

Visit http://www.dovepress.com/testimonials.php to read real quotes from published authors. 